Article

\title{
Cascade Use and the Management of Product Lifecycles
}

\author{
Matthias Kalverkamp ${ }^{1, *}$ (D) Alexandra Pehlken ${ }^{1}$ and Thorsten Wuest ${ }^{2}$ \\ 1 Department of Business Administration, Economics and Law, Cascade Use Research Group, \\ Carl von Ossietzky University of Oldenburg, Ammerländer Heerstr. 114-118, 26129 Oldenburg, Germany; \\ alexandra.pehlken@uol.de \\ 2 Industrial and Management Systems Engineering, Benjamin M. Statler College of Engineering and Mineral \\ Resources, West Virginia University, Morgantown, WV 26506, USA; thwuest@mail.wvu.edu \\ * Correspondence: matthias.kalverkamp@uol.de; Tel.: +49-441-798-2861
}

Received: 23 June 2017; Accepted: 25 August 2017; Published: 29 August 2017

\begin{abstract}
This paper explores the challenges related to the End-Of-Life phase of products and circular systems of reuse and recycling within the commonly established frameworks of product lifecycles. Typically, Original Equipment Manufacturer-centric supply chain perspectives neglect the complexity at the End-Of-Life where many third-parties are involved in reuse and recycling activities. Based on a review of product lifecycle and related recycling literature, this study proposes the application of 'cascades', a term originally coined within the biomass domain. We propose and subsequently apply the 'cascade use methodology' and identify additional and value-adding End-Of-Life solutions for products and materials. The adoption of cascade utilization into product lifecycles is analyzed and critically discussed using case studies from independent remanufacturing and tire recycling, focusing on the End-Of-Life while excluding business models as renting or sharing. Although theoretically feasible, we argue that the practical adoption of 'cascade use' deserves more attention from researchers and practitioners in order to become an integral part of the comprehensive management of product lifecycles.
\end{abstract}

Keywords: product life cycle; cascade utilization; recycling; reuse; remanufacturing; Closed-Loop Supply Chains (CLSC); Product Lifecycle Management (PLM)

\section{Introduction}

The circular economy seems as if it will be a driving force in the manufacturing and service industry in the coming years [1]. An increasing awareness for environmental impacts [2], combined with increasing material demand [3] and volatile resource and energy prices persuade industries to seek alternative End-Of-Life (EOL) scenarios. Sustainability is gaining importance, most notably because policy intervenes with the objective of reducing the environmental impact of EOL products [4] or to reduce negative societal externalities, which is the purpose of the Dodd-Frank Act in the United States (US) regarding the trade of conflict minerals [5] (Sec. 1502).

The waste management hierarchy classifies EOL treatment options in order of environmental friendliness, with landfill at the bottom and the final sink to prevention at the top of the hierarchy [6]. In a circular economy, products and materials are supposed to be maintained in iterative cycles of reuse and recycling, which are located in the middle of the waste management hierarchy. Reuse and recycling are preferable from an economic and environmental perspective due to their residual value in the form of raw materials, labor, time, and energy [7]. However, a sustainability-driven decision between reuse or recycling is most likely product dependent [8]. So, what does circular economy stand for in reality, and how does the circular economy fit with existing product lifecycles (PLCs)? This paper provides an overview of popular PLC perspectives and elaborates on how they fit into 
the cascade utilization of products and materials. An analysis of two cases from distinct automotive components supports the evaluation of cascade utilization and the formulation of implications for the management of product lifecycles. This paper argues that complexity at the end of PLCs requires managerial awareness beyond existing lifecycle management approaches in order to achieve a circular economy. In that capacity, this paper is focusing specifically on the End-Of-Life phase of products while initially excluding business models such as renting or sharing. However, innovative and novel business models are considered in the analysis because new models are likely to emerge from a more transparent and structured understanding of the often-overlapping interface between End-Of-Life and Mid-Of-Life reflected by cascade use and lifecycle management implications. This paper aims at improving the fundamental understanding of lifecycle challenges and will therefore serve as a basis for more in-depth work focusing on business models, innovation and their implications on sustainability.

The release of the circular economy strategy of the European Commission (EC) in 2015 [9] rose awareness for a more sustainable use of resources, even though recycling technologies and industries were already an integral part of the current market systems. Reuse and recycling transactions are fundamental for a functional circular economy and they regularly form some sort of cascade utilization. Within a PLC, there may be several cascade levels (reuse, recycle, recover), where waste streams of products, components and materials are separated; some streams remain at certain levels for lifecycle iterations, other streams flow towards alternative lifecycles. At this point, the complexity of cascading already emerges, since it is either material or component oriented and could enter closed-loop or open-loop lifecycles. Within the closed-loop cycle perspective, a component will be reused or recycled for the same application (a tire becomes a tire again), whereas in an open-loop perspective, materials and components enter another application (a tire becomes artificial turf). Therefore, the perspective taken is essential to understand the PLC: from the product system perspective, the materials may enter different loops of different products via open-loop recycling. However, from the material flow perspective (macro view), they are still reentering the material loop. Incorporating these different perspectives is one of the objectives of the cascade use methodology presented in this paper. The general concept of eco-industrial networks illustrates how such cascading use serves sustainability objectives [10]. Figure 1 illustrates an ideal circularity that emerges from the reuse and recycling of products, components and materials within the automobile sector. Of course, reality shows a different picture and often materials end up in in different industry sectors, considered as open-loop cycles. Such alternative reuse and recycling options may be reasonable too. The objective of cascade utilization is to delay inevitable final sinks such as energy recovery (and landfilling) by retaining products, components and materials on higher cascade levels for longer periods. This objective is in line with the concept of the circular economy [1]. Figure 1 demonstrates in theory the closed-loop lifecycle of various cars starting from the production, followed by use, reuse and recycling phases, resulting in a percentage of the material flow in the energy recovery. Remaining materials and car components with no energy recovery option should stay in the loop, for example, as remanufactured components. Following the hierarchy of the circular economy, reuse and recycling should be prioritized before inevitable sinks. In the real world, it is more likely that the bulk of materials is entering different loops of different products as open-loop cycles as well; those alternatives are not shown in this figure, although the dynamics of open-loops and the resulting complexity is discussed in this article. Nevertheless, in the real world, the most common PLCs happen to be open-loop cycles and this paper highlights the various challenges in handling the different perspectives.

The PLC approach is a central element in the development of more sustainable products. For example, product design (e.g., design for recycling) or product business model design (leasing vs. transfer of ownership) may have an influence on sustainability [11]. Throughout the PLC, products return to the manufacturer or flow towards third parties. In this context, Closed-Loop Supply Chains (CLSCs) contribute to circular PLCs as they provide the managerial and operational methods and tools to connect PLCs through reverse logistics processes [12]. PLCs may be further closed because third-party organizations take advantage of materials dedicated to waste management. 
However, the re-collection of product and material flows is an increasingly complex task. In addition, a circular business model inherits a greater business risk than linear business models [13]. Furthermore, legislations heavily influence product, information and material flows.

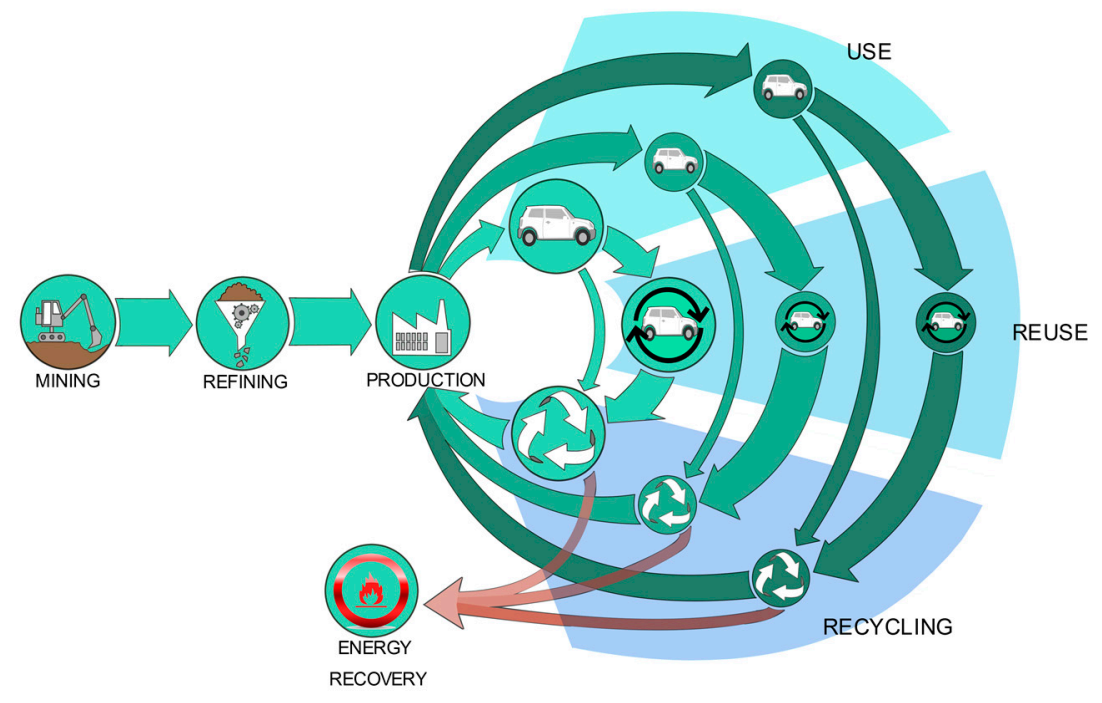

Figure 1. Simplified ideal closed-loop cascade approach in the automobile sector (own figure).

In this paper, we argue that the current perspectives on PLCs often neglect the full complexity at the EOL and that these perspectives should extend to open-loop cycles. The full complexity may be neglected because current observations on PLCs as well as on circular economy concepts and business models focus on single businesses or product service systems within corresponding system boundaries [14], such as a particularly defined (closed-loop) supply chain. Within such supply chains, open- or closed-loop reutilization strategies are discussed, however, the potential of such open-loops is usually contextualized within closed-loop supply chains [15] while the potential of 'open-loop', i.e., forward supply chains for both open- and closed-loop reutilization strategies remains less appreciated by literature.

Two guiding research questions motivate and shape this study: (1) can 'cascade use' considerations meaningfully extended the view on the EOL within PLCs to better understand and provide a possible structure for the complexity and dynamic at the EOL, and (2) how can a cascade use methodology contribute to a more sustainable management of product and material lifecycles? Considered the relevant literature and case studies, we provide a definition for cascade utilization that serves as an extension of lifecycle perspectives in order to reflect the broad variety and complexity of different EOL options for the sustainable management of PLCs, including both open- and closed-loops. Therefore, we propose to consider 'cascades' in the comprehensive management of PLCs to support the shift towards a circular economy. The following Sections 2-4 focus mainly on answering the first guiding research question. In Section 2, the paper analyses the existing PLC perspectives, discusses the variety of EOL viewpoints and points out cascade utilization at the EOL. Thereafter, in Section 3, cascade use is proposed as a methodology to extend the management of PLCs in order to comprise the complexity of circular PLCs. Section 4 models and critically assesses the cascading PLCs of two case studies, covering one open-loop and one closed-loop case. Section 5 eventually aims at answering the second guiding research question by discussing the implications of the approach, its theoretical and managerial contributions, as well as posing limitations, persisting gaps and challenges. Section 6 concludes the paper and provides an outlook on further research directions.

\section{Product Lifecycle and Complexity at the End-Of-Life}

This section analyzes the predominant PLC perspectives, namely the marketing and the technical process/engineering perspectives. Furthermore, a discussion on the End-Of-Life within the different 
PLC perspectives sheds some light on the currently existing variety of viewpoints. Finally, this section argues the suitability of cascade utilization during the EOL and provides a first case study set in automotive alternator remanufacturing.

\subsection{Product Lifecycle Perspectives}

The term product lifecycle (PLC) is used differently in literature [16]; two central models emerged that gained wide acceptance within the community [7]. We refer to these two models as different perspectives on the PLC since they cannot be fully separated when considering the real-world complexity of market-oriented manufacturing. We illustrate challenges related to these two perspectives throughout this paper. An overview of selected lifecycle-related publications shows that even these two distinct models involve a certain variety.

The PLC from a marketing perspective identifies four to five stages, depending on the source [17], namely: introduction; growth; maturity; saturation; and decline. This classic PLC perspective particularly relates to sales volumes, according marketing strategies and profit potential $[18,19]$. The complexity of this PLC perspective increases once the lifecycle of a particular product is further differentiated into product class, form and model [17].

Figure 2 shows the classic PLC model by [20] represented by a dashed line and incorporates additionally an extension to the model including multiple PLCs (class, form \& model) based on [17] represented by black lines. Overall, this marketing perspective is valuable when looking at marketable issues such as sales, supply and demand planning, and new use lifecycles. Those issues become relevant when planning return flows of products, for example for reuse or recycling; because throughout the different PLC stages amounts of return flows vary. It is possible to combine and/or extend the lifecycle of a product, for example, through identifying and developing new uses or markets [20]. We will refer to this as the marketing lifecycle perspective in the remainder of this paper.

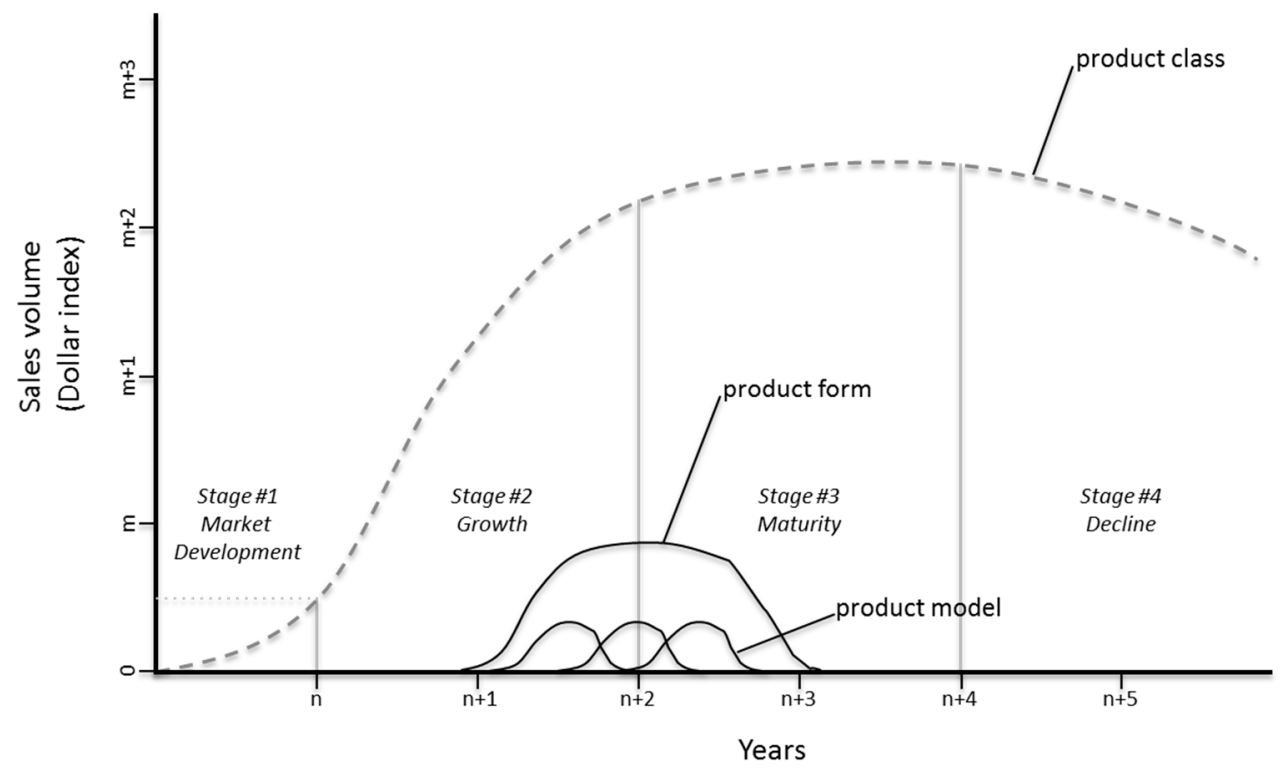

Figure 2. Marketing product lifecycle and product aggregation levels (based on $[17,20])$.

The alternative lifecycle perspective focuses on materials, information and resources, which are extracted, produced, manipulated, communicated, used and generally disposed of through the relevant processes. The different phases in this more engineering focused lifecycle perspective are usually separated in three overarching phases: Begin-Of-Life (BOL); Mid-Of-Life (MOL); and End-Of-Life (EOL) (see Figure 3), while paying most attention to BOL and MOL. 


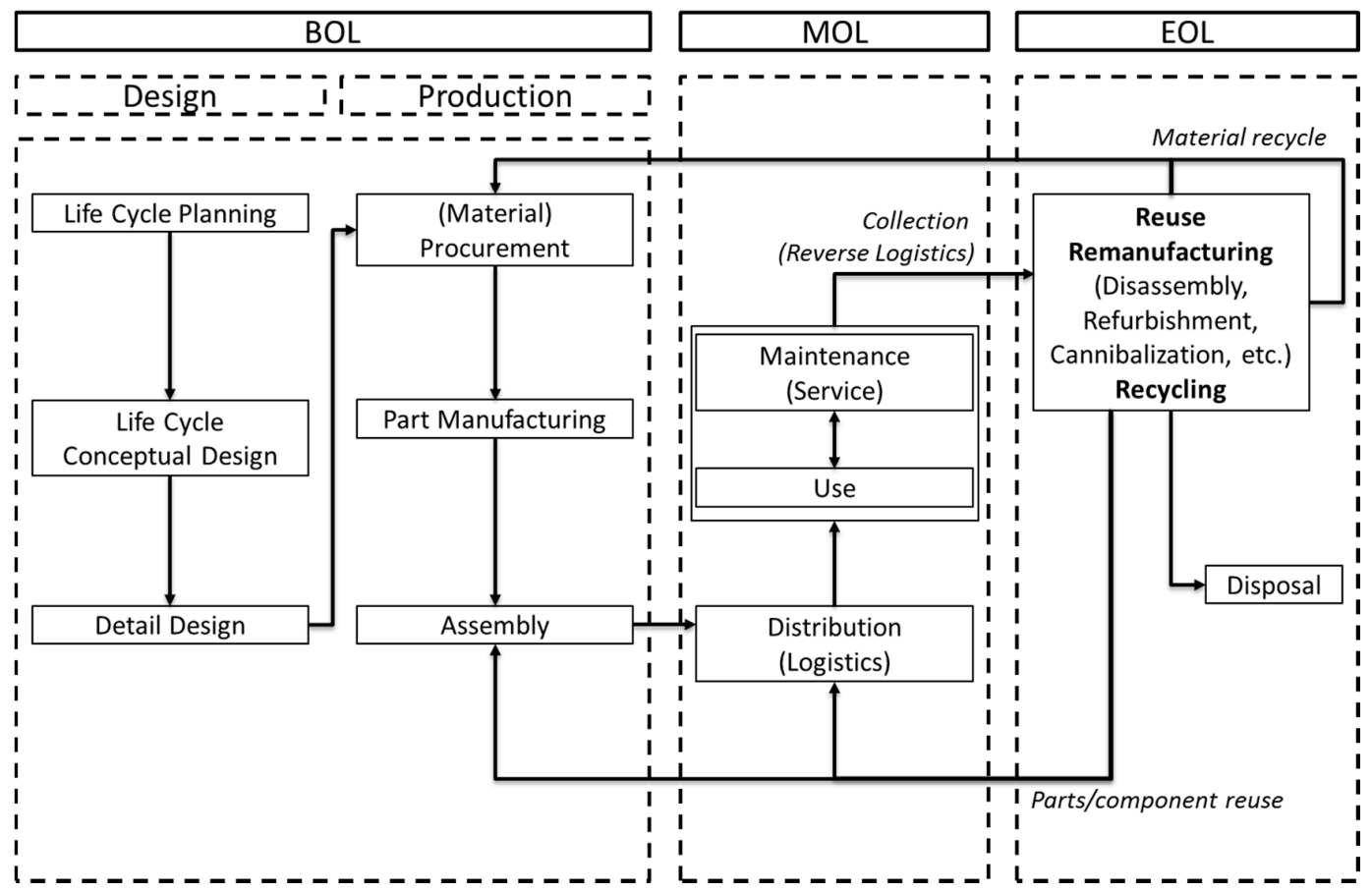

Figure 3. Technical three-phase lifecycle with material flows (extracted from [21]), depicted flows implicitly cover financial (reverse) and information (bi-directional) flows.

In contrast to the marketing lifecycle perspective, we refer to this as the technical lifecycle perspective. The technical lifecycle perspective is commonly used in environmental research, for example, in the Life Cycle Assessment (LCA). Business process management also makes use of the technical perspective, a domain of application is PLC management (PLM). Both LCA and PLM consider or encourage a potentially circular flow of products and materials. LCA is a method to evaluate the environmental impact of a product throughout its life from the source, through production and usage, until disposal-and potential reutilizations [22,23]. PLM focuses on the feasibility of the PLC using data and information technology [21,24,25]. However, consistent and consequent implementation of PLM requires a suitable business strategy which in turn also requires taking the marketing lifecycle perspective into consideration to be ultimately successful [16]. Consequently, there is no black or white separation, but merely a separation by emphasis.

The marketing and the technical perspective both claim to focus on the whole lifecycle. Besides the PLC perspective, a process-related, functionalist perspective exists in marketing, which includes all market transactions from the (primary) seller to the ultimate consumer, also referred to as 'transvections' [26]. These transvections somehow reflect the technical process 'from extraction to consumption' [27]. These process-orientations merge into the concept of Supply Chain (SC) management [28]; this also illustrates how the two different lifecycle perspectives have strong linkages and interdependencies with each other in common business practice.

Both lifecycle perspectives have to consider what happens beyond 'the final phase' (decline or EOL) in order to achieve more sustainable products and business models in general. The following sections focus mainly on the technical lifecycle perspective, based on the three main phases BOL, MOL and EOL.

\subsection{End-Of-Life in Product Lifecycle Perspectives}

Despite its importance for a more sustainable management of resources, there is no standard definition of the EOL. As mentioned earlier, the perspective is highly important. In addition to the material and component perspective, an environmental and economic perspective raises the complexity even more. From an environmental perspective, when products reach their EOL, they are supposed to 
be reused or recycled in order to extend product and material life. From an economic perspective, reuse and recycling preserves value in terms of resources, labor and knowledge, amongst others. Therefore, several lifecycle models feed EOL products back into the lifecycle at various stages, depending on the chosen EOL strategy (see Figure 3). However, one fundamental question remains unanswered: 'when does a product reach its EOL?' Although there is no universally accepted definition, in the following, a selection of current perspectives illustrate the challenges and inherited complexity of the EOL culminating in an attempt to answer the above question at the end of this section.

From a marketing and sales perspective, the product reaches its EOL when it is not sold, supported or serviced anymore. A consumer might use a product for years to come, but the producer does not have an interest in the product anymore. These circumstances present opportunities for third parties to further extend PLCs with new and innovative business models. In the case of leasing or renting, the producer or distributor can freely define when the product is considered to have reached its EOL. Especially for planned reuse, a pre-defined EOL may help to ensure quantity, quality and timely returns, which are important to ensure manageable product flows $[7,17]$. A current example for planned EOL is the mobile phone sector, where mobile phones become obsolete even though they are still fully functional due to the absence of software updates.

The product and material perspective puts a stronger emphasis on the physical state. A product is considered to have reached its EOL, when any form of technical reason deems it unusable for its intended purpose. The limitations of reuse and recycling suggest a division into the material centric approach and the product centric approach [3]. A material can maintain or lose its functions and experience fatigue, thus becoming a potential safety hazard. It reaches its EOL mostly due to physical constraints, such as a rubber insulation material that decomposes by permanent sunlight and becomes porous. In contrast, a product might lose its function and therefore reach its EOL, for example, because a crucial mechanism might be broken due to a loose connection. Here the material might still be as good as originally intended. Therefore, an EOL product (function) can often be repaired whereas an EOL due to material issues often becomes waste.

Legal constraints affect both the marketing and the technical perspective. When a user discards a product within the EU, it legally becomes an EOL product $[29,30]$. Laws can also regulate whether a product is allowed for sale or usage, for example in the case of hazardous materials, such as a leaking battery. Hence laws may define the EOL beyond a marketing or functional perspective. Naturally, this often varies from country to country.

EOL could be further differentiated in "end-of-use" and "End-Of-Life". In this case, EOL defines the state where reuse is not an option anymore and products are to be recycled [12]. The 'end of use', in contrast, occurs when a product is not used any longer due to technical restrictions but is theoretically still in a usable state; personal computers that reach their EOL as they are outdated in terms of processing power are a current end of use example.

The presented overview of different perspectives of a product's EOL partly transports the complexity entailed in regular PLCs and therefore gives an outlook on the expected complexity of truly circular PLCs. It is apparent that the currently used PLC models are not fully equipped to reflect the complex and dynamic nature of this transition phase comprehensively. For the cascade use methodology, all perspectives of the EOL are relevant as they may indicate different cascade levels where one PLC ends or splits up, and another PLC starts. Therefore, the cascade use methodology refers to the EOL as to 'where one product lifecycle ends and at least one new PLC starts at any of the cascading levels of reuse, recycling or recovery'. This definition implies the vision of a circular economy with almost no landfill; the cascade use methodology considers landfill as the final and undesirable EOL.

\subsection{Application of End-Of-Life Perspectives}

PLC illustrations in the literature model the lifecycle differently, they include or exclude certain process steps, they extend the perspective by additional processes, or they adjust the allocation of reverse flows. The following applications of EOL lifecycle perspectives are not exhaustive; they rather 
serve to illustrate the necessity of cascading use in the management of PLCs. A more comprehensive overview of the existing variety is provided by [31] for the interested reader.

Ref. [32] describe a SC model according to the technical lifecycle perspective. They recognize a central role for a distributor when they distinguish between open- and closed-loop supply chains and allocate the reverse flows in Closed-Loop Supply Chains towards the distributor. They use their model to identify "the optimal strategy ( . . ) for a manufacturing company". However, they neglect other flows passing by the distributor. Such flows could re-enter the previous and/or enter other lifecycles. We will tackle this aspect, which is to the knowledge of the authors hardly considered with all of its consequences by academia today, with the proposed cascade use methodology in the following section.

Ref. [16] distinguishes three perspectives within the technical lifecycle perspective, namely innovation, production, and materials. These three perspectives do not necessarily cover all three phases of BOL, MOL and EOL. Furthermore, the perspectives exchange information in the sense of PLM at distinct steps. He identifies these exchange relations for a potential integration of the three perspectives.

A more detailed analysis of the technical lifecycle perspective presents some interesting differences. These models usually start with the raw materials or the extraction process. Following steps related to processing, such as production or fabrication. However, the purpose of the observation changes the depicted processes. For example, Ref. [33] focus on EOL solutions and identifies the steps parts fabrication, parts assembly, product assembly and distribution; and finally users. They also identify a service process between fabrication or assembly and distribution. Their circular flows feed from the users back to all other processes. Their EOL focus stems from the extended producer responsibility incorporating a detailed distinction of eight EOL solutions. Although similarly from a technical perspective and with a focus on EOL, the model by [34] has four EOL solutions and fewer processing steps than [33]. They only separate 'material extraction \& processing' and 'manufacturing \& assembly'.

Furthermore, Ref. [7] considers the marketing lifecycle perspective for their research on remanufacturing. For remanufacturing, uncertainties about returned products, such as quantity, quality and time are very important. Hence, they investigate how the PLC affects return flows and remanufacturing strategies. Similarly, Ref. [17] investigates how different sales patterns during the lifecycle affect reverse logistics.

Without neglecting one or the other lifecycle perspective, we believe that the EOL deserves additional attention. Although a lot of research considers EOL strategies, developed models miss the complexity existing at or emerging from the EOL. In their EOL strategies, models usually identify various reverse flows. Further, most of the models either directly or indirectly assume that the manufacturer or distributor manages these return flows through PLM, CLSCs and reverse logistics strategies. However, the market reality influences the actual product and material flows at the EOL, flows may split up or may not merge as planned. The latter occurs because the collection of used products is a crucial point in reverse logistics, where the Original Equipment Manufacturer (OEM) or other EOL stakeholders seek to collect EOL products from the final customer. Therefore, the management of PLCs must consider a greater variety of additional lifecycles stemming from various EOLs occurring during the product or material life. This gap in the current state of the art in lifecycle modeling is highly relevant and will therefore be investigated in more detail here using real world cases.

\subsection{Cascade Utilization at the End-Of-Life}

Thinking in cascades should ideally influence the PLC from its very beginning. For example, Design for Environment and Design for Remanufacture are design principles that consider EOL options for a product during the BOL phase [11]; there are also products that were never designed following any of these principles. During the MOL phase, the product quality, the type of use (e.g., other than intended) or even misuse may influence potential reuse. At the EOL, decisions about different EOL options must be taken. Products eventually reach their EOL and hence reach one of the many stakeholders at the EOL. Those stakeholders might be OEMs, independent remanufacturers and recyclers, municipal waste management systems, scrap yards, second hand dealers, or others. 
These stakeholders then decide upon the cascade channel for a product or upon different channels for the product's components, thus about potentially following PLCs.

We assume that a product, although it might be designed for reuse, may not end up in the initially intended EOL channel. For example, an alternator from a passenger car, which can be remanufactured, may be replaced during maintenance in an independent repair shop. There it is replaced with a remanufactured spare part from an independent remanufacturer. Aside from the OEM, who produced the original alternator, an independent remanufacturer now receives and remanufactures the used alternator.

The case of (starters and) alternators represents the most developed part of the automotive remanufacturing market in Europe and the US. Starter and alternator remanufacturing highlights the potential and the inherited complexity of EOL options and its implications on the management of cascading PLCs. Remanufactured starters and alternators have an approximate share of $80 \%$ of the total replacement demand for these components in Europe. Although OEMs remanufacture approximately $75 \%$ of all remanufactured starters and alternators, independent remanufacturers are still responsible for $25 \%$ of all remanufactured starters and alternators [35]. For other components, independent remanufacturers account for greater shares of the remanufacturing market, such as for power steering (approx. 55\%) or brake calipers (approx. 83\%) [35]. The potentially different channels of remanufacturing indicate the complexity at the EOL during a particular lifecycle of an automotive component. This complexity grows with each additional EOL option, such as plain reuse or material recycling, because different stakeholders are involved in according market channels. This complexity stems from (unintended) product flows and extends to interrupted or missing information flows, which could improve the overall management of the PLC. To address this complexity stemming from multiple EOL options, we propose adopting a model from the biomass domain that originally identifies cascades for renewable materials.

\section{Cascades for a More Comprehensive Management of Product Lifecycles}

We believe it is crucial to rethink the way we look at the product and material End-Of-Life today in order to change the way we manage the EOL. The cascade use methodology offers a broader perspective on the EOL. Considering complex cascades at the EOL in a PLC model is a new approach. Instead of assuming integrated reverse flows from the EOL towards predefined reuse and recycling processes, we argue that highly integrated and totally market oriented and intermediate organizational types coexist and are even available for the same product. It should be noted that modeling for Life Cycle Assessment (LCA) discusses this complexity at the EOL between reuse, recycling and recovery when dealing with multi-functionality, i.e., questions of subdivision, substitution, or allocation [36]. However, we focus on the EOL complexity from a rather operational perspective asking how to manage the product lifecycle under such complex circumstances.

The visualization of different cascades allows for the identification of alternative EOL solutions. Furthermore, it incorporates market realities of trade with and reuse and recycling of used products and materials. The realities at the EOL are neither a circular flow towards perfectly known stakeholders nor are they as one-directional as critics of classic forward Supply Chains may claim. To classify the cascade use methodology in the context of the management of PLCs, the following sections focus on the transfer of the cascade utilization approach from the biomass domain to the PLC domain.

\subsection{Cascade Utilization: Learning from the Biomass Domain}

Cascade utilization is a concept that originates from the biomass domain. Biomass can be considered a renewable resource and can provide energy in closed eco-systems when its natural basis, such as vegetation, is managed in a responsible manner [37]. The system itself is closed, as the carbon stays in the cycle, but a product lifecycle is missing. Cascade utilization processes components of renewable resources in different applications before these components are treated as an energy source as final sink. As per definition there is no waste stream since, in an ideal case, everything is being reused, recycled, and converted into energy. A typical example for a renewable resource is wood, 
more precisely lignocellulose. From products such as wood panels and fiberboards, the cellulose fibers become pulp in the next cascade level, to be used in products such as tissue paper; in the final cascade, power generation uses the fibers as fuel for energy [38]. In this example of cascade utilization, shown in Figure 4, the product passes the reuse cascade level and enters the recycling level directly. Otherwise, the wood panels would have been reused before. Furthermore, the wood could have been used in power generation, i.e., energy recovery immediately, passing both reuse und recycling cascade levels.

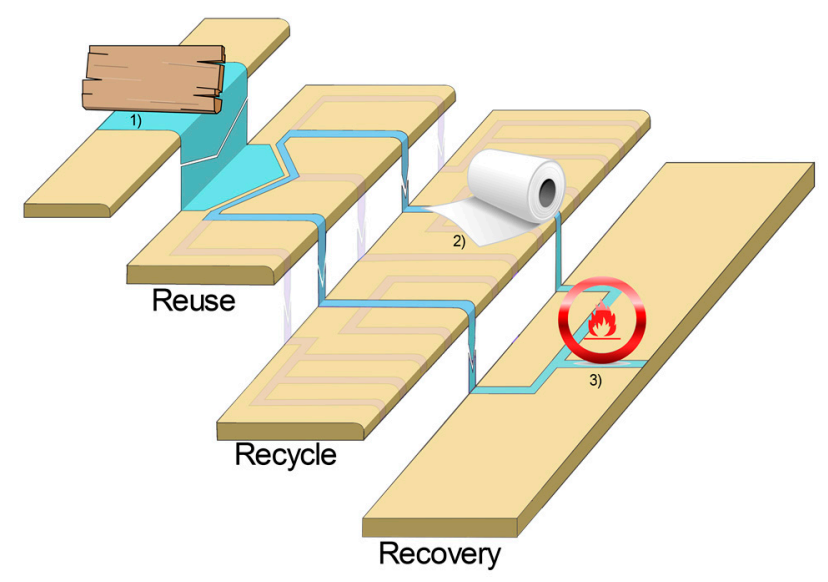

Figure 4. Cascade Utilization of wood/lignocellulose.

The biomass case rather describes a cascade utilization in an idealized form compared to the technical lifecycle where the cascade may already be planned to start during the BOL. The challenge is to plan a flexible cascade in the beginning of a product's life with the desirable outcome of keeping almost all materials in the circular loop, ultimately resulting in nearly no final sinks that have to be disposed of.

The terms "cascading" and "cascaded use" have been further used in lifecycle management related contexts outside the biomass domain for several years. For example, Ref. [39] describes a "cascaded lifecycle" for Li-Ion batteries, first used in electric vehicles (EV) and thereafter in stationary applications. However, their study does not consider different options at the end of the first lifecycle, which is the EOL of the EV battery. Furthermore, the study does not discuss alternative secondary lifecycles or lifecycles of those parts of the battery that are removed during the repurposing process. The cascade use methodology considers such repurpose lifecycles like the EV battery as well, though the EV battery would be a component of the original product (the EV) in which the battery is one component. Furthermore, related to quantitative approaches in Closed-Loop Supply Chains, Ref. [40] uses the term cascade in the context of reuse ('cascade reuse opportunities') where they further state research gaps regarding a 'life-cycle approach' that considers all the different types of product returns.

\subsection{Cascade Utilization in Management}

The cascade use methodology considers the broad variety of EOL options that cascade products and materials into reuse or recycling and eventually into recovery, according to the biomass approach. This encompasses the opportunities and challenges inseparably linked with EOL options and according stakeholders.

The cascading use already begins during the production of raw materials required for production. By-products and waste streams from production are reused in other products or recycled in order to produce secondary resources. Furthermore, some resources are used in energy recovery processes. Reuse, recycling and recovery form part of the waste management hierarchy that provides a guideline for the management of resources [6]. The presented cascade use methodology focuses on the EOL of the final product and its components, due to the complexity at this point in the PLC. Different than during 
the BOL phase, the manufacturer has much less control over reuse and recycling options at the EOL. The cascade use methodology acknowledges the different potential stakeholders at the consecutive EOLs. The stakeholders may vary due to distribution strategies (usage vs. consumption) or due to the PLC iteration; a car might reach an EOL in one market but start another lifecycle elsewhere. Similarly, car components are exchanged and reused or remanufactured before they are recycled. Therefore, the cascade use methodology further recognizes that a SC owner can hardly manage all the potential EOL scenarios that emerge. The cascade use methodology rather indicates all potential EOL options supporting managers and other decision makers to identify economic and environmental potential. During the product life time, the relevance and importance of cascade use levels may change, some EOL options might no longer exist while new EOL options emerge. Reasons may be manifold, for example, fluctuations in raw material prices or changes in customer preference. Such changes may not be foreseen during the product development or at the time of market introduction. However, outlining the predicted cascading use and a constant revision of the cascading options during the PLC allows for a lifecycle management beyond a first or second product life. Such management of the PLC would have to recognize the existence of third-party stakeholders in EOL Supply Chains. Some of these stakeholders might be well known, while others are new or on distant (unserved/under-served) markets, or both.

Taking the waste management hierarchy as a reference, in combination with the biomass cascade, the cascade use methodology outlined in Figure 5 illustrates the increasing complexity and variety of EOL options at the levels of reuse, recycling and recovery. Although inclining downwards, the cascades can even provide up-cycled materials at the recycling stage or "better-than-new" products at the reuse stage. Those outputs remain at their corresponding cascade level, though at a higher level than down-cycled materials or simply reused products. This cascade does not consider landfill. First, because landfill does not contribute to circularity. Second, although limited to certain global regions, landfill is either illegal or limited. For example, the European Commission adopted its Circular Economy Package with new targets for landfill and a landfilling ban for separate waste (among other objectives) [9].

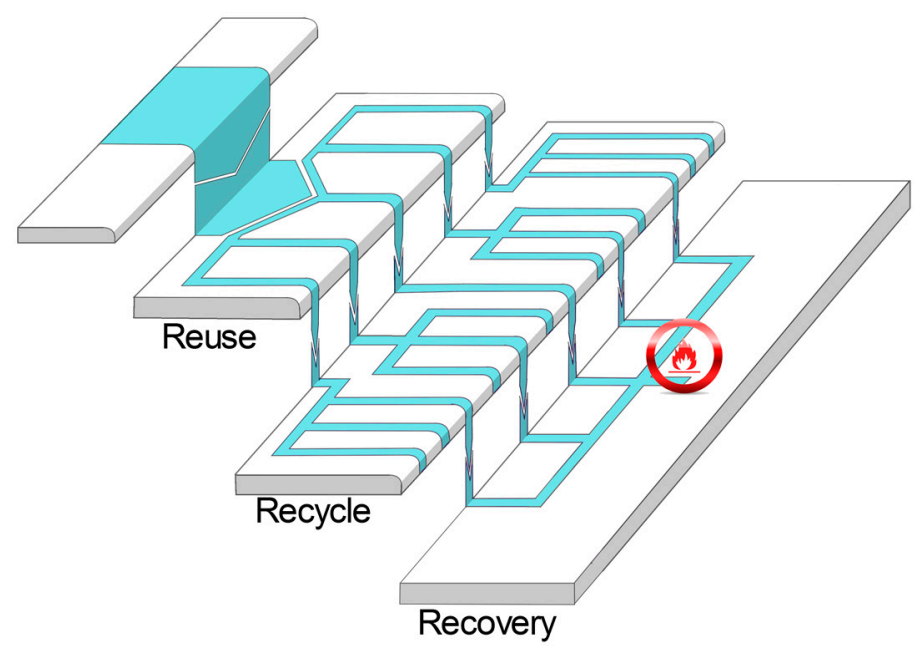

Figure 5. Cascade Use Approach.

\section{Case Studies: Product Lifecycles Diverging into Complex Cascades}

This study's guiding questions ask whether a 'cascade perspective' helps to better understand the complexity of PLCs at the EOL, and whether the cascade use methodology can contribute to a more sustainable management of product and material lifecycles. The previous sections revealed a gap in existing PLC perspectives on the EOL which motivated the development of the cascade use methodology. In the absence of relevant literature, an empirical, case-based approach is applied for the analysis and discussion of the methodology. Applying automotive-related case studies to the 
cascade use methodology supports the evaluation of the proposed extension of the management of PLCs; the case-based evaluation is similar to [1], who make use of settings as revelatory cases. Further examples in related domains for the use of cases as a means to evaluate new methodologies are [41,42]. Similar to [1], the cases have a revelatory character and represent one open-loop (tires) and one closed-loop (suspension control arms) system. Further distinctive factors motivate the case selection. The tire case represents a commonly recognized automotive product that can be utilized by all three cascade use levels. By contrast, suspension control arms provide a case of commonly less-known products in which very few utilization options at the different cascade levels are established. All cases are based on empirical data from research conducted by the authors. The case descriptions indicate the data origins in more detail. Automotive lifecycles serve as good examples for a great variety of End-Of-Life options, as shown previously with the example of starters and alternators remanufacturing. In the EU, policy intervenes especially at the EOL vehicle (ELV) market, as well as at the aftermarket. This intervention marks channels towards recycling and reuse. Furthermore, the international trade with used cars and used parts as well as established recycling and remanufacturing industries in regions such as Europe, allow for a variety of secondary PLCs for vehicles and components.

\subsection{Closing Product Lifecycles with Cascade Utilization}

The assumption of Closed-Loop Supply Chains where products and/or components flow from the EOL into new or iterative lifecycles or cascades, works for some products. Therefore, the majority of examples for closed lifecycles refers to CLSCs and especially to reuse and remanufacturing; examples stem from copiers, aviation equipment, automobile parts, and computers, amongst others [43-46]. The reason for the success of these business-models is their foundation in CLSCs that do not involve a transfer of ownership between producer and user or that use incentives such as deposits or bonuses for returns; both approaches can effectively support in closing the loop at the EOL. Regularly, leasing and renting models are proposed to support a circular economy instead of direct sales [47]. Such models were not considered in the methodology development as they usually reduce the observations to closed-loop supply chains therefore by default to closed-loop systems. Nevertheless, there are limitations to these approaches because Original Equipment Manufacturers have different options to deal with returns whereof one is the destruction of returned products $[45,48]$. In addition, market reality may work against integrated lifecycles. For example, due to cultural circumstance, maintaining ownership might be valued higher than the pure usage [14]; or in the case of incentive-based reverse SCs, the incentive is offset by another stakeholder at the EOL, for example a scrap dealer pays more than the deposit value for a product due to the price volatility at raw material markets.

Although some products are suitable for CLSCs with leasing, especially at business-to-consumer markets, the transfer of ownership is predominant [14]. Despite a sometimes-postulated trend towards more leasing and renting models for typical consumer goods, full control over EOL strategies by either manufacturers or policy is difficult to achieve. Furthermore, classic SCs may allow for product improvements through third parties at the EOL. For example, an independent remanufacturer for mechatronic components claims to improve the original design of a throttle body, well-known for its failures [49], which makes it 'better than new'. Besides economic benefits for the independent remanufacturer and its customers, such solutions improve the environmental assessment too. This kind of innovation could be at least be hindered with preemptive strategies. Due to leakage from closed-loop systems, different stakeholders close product and material lifecycles. The cascade use methodology supports circularity by acknowledging that open- (i.e., forward) and closed-loop SCs regularly co-exist and jointly provide environmental and economic benefits.

The following cases show how products and materials cascade through reuse, recycling and recovery. Different stakeholders deal with products and materials in their individual way through the cascade use levels. The level of efficiency varies throughout these levels and while some options become less profitable or prohibited new options arise, developing and eventually establishing new flows through the different levels of the cascade. 


\subsection{Case Study: Tires}

The first case study in this section represents car tires and shows how products enter markets that they were never intended or designed for, explaining the dynamics in an open-loop cycle. The data for this case was collected by one of the authors of a research project performed in Canada [50] and was then further studied in Europe. Due to the good material properties, car tires could be further used as tires or as materials for other products. Car tires are mainly produced of natural and synthetic rubber, steel, fiber and chemical additives. Passenger car tires tend to contain more synthetic than natural rubber; truck tires consist of more natural rubber; and off-the-road (OTR) tires have nearly no synthetic rubber. The rubber composition may be because passenger car tires must meet higher quality standards (e.g., [51]) to succeed in the competitive market. In contrast, truck and OTR tires must cope with heavy loads and longer distances rather than high speed. The fiber content in passenger tires can be as much as $5 \%$ of the total tire weight, whereas OTR tires tend to have little or no fiber content and contain about 15\% steel [50], The purpose of fiber and steel in the tire is the reinforcement of the rubber. To fulfill their function, the reinforcements should be as inseparable from the rubber as possible [52].

These properties and high quality clearly demonstrates that there is an interest in this product. Nearly every country tries to eliminate old tire pile sites and each tire is going to be recycled after its usage. The cascading use of tires is therefore dominant in many countries. Figure 6 shows the tire cascade utilization, at the top level are used tires (1). First cascade is the reuse of the tires as such without any remanufacture (2). For example, tires from Germany are legally reused in neighbor countries as Poland or Czech Republic where a lower tread depth of tires is tolerated. Tires with too low tread depth could be retreaded, which involves a new layer of rubber on the tire surface. This is similar to remanufacturing, though with lower quality compare to the original tire. At the next and most favored cascade level (open-loop) in industry, the tires could be recycled and the materials are used as a basis for new products besides tires. For example, steel could be melted in steel smelters (3) and then further used anyway as recycled steel. Rubber turf and rubber particles are used in artificial turf or as shoe soles (4). The fiber is mainly being used as substitute fuel due to the high energy content (5). Using the 'energy recovery' cascade level should always be the last resort for cascading since there is currently no further cascade level after the energy recovery.

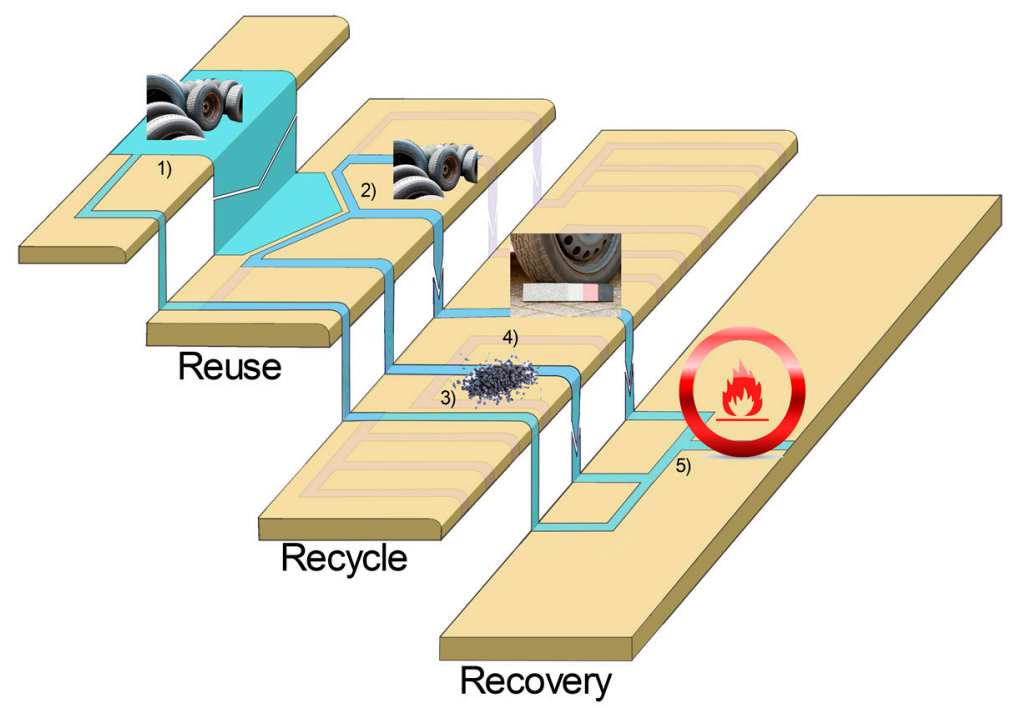

Figure 6. Cascade Use of Tires.

Considerations concerning GHG emissions and human health have been evaluated in detail in another study [50]. Comparing the manufacture of a new tire with the retreading of a scrap tire, a new tire has a much greater impact on the environment than a retreaded tire. The potential for GHG 
emissions is 1.8 times that of a retread. With $974 \mathrm{MJ}$ of energy needed to manufacture a new passenger tire and only $400 \mathrm{MJ}$ needed to manufacture a retreaded tire, this corresponds to energy savings of $59 \%$ [50].

Material recovery and reuse for its originally intended purpose is highly recommended. Rubber crumbs can be used either in new tires or in other rubber products. Because the energy content in a passenger tire (PT) is about $260 \mathrm{MJ} / \mathrm{PT}$, the energy to process tires to crumbs should not exceed this amount in order to be environmentally feasible. The energy used to manufacture a new tire is $103 \mathrm{MJ} / \mathrm{kg}$, which translates to GHG emissions of $6.9 \mathrm{~kg} \mathrm{CO}_{2}$ per $\mathrm{kg}$ of tire manufactured. Replacing virgin synthetic rubber with recycled rubber, depending on the processing method, can reduce these emissions. In the case of energy recovery, another option for processing scrap tires, tires produce higher $\mathrm{CO}_{2}$ emissions than oil and natural gas, but lower emissions than coal.

Recycling costs are varying because the energy costs are country-specific. Furthermore, raw material prices influence the recycling decision since the natural rubber price is varying and potentially putting pressure on the tire manufacturer. Table 1 provides energy indicators for tire recycling, for example in line two, the calorific value of used tires is approx. $9 \mathrm{kWh} / \mathrm{kg}$. The energy indicators and the market price for natural rubber (see Figure 7) may build the basis for a decision pro or contra the economics of a recycling case.

Table 1. Energy consumption for mechanical scrap tire processing ([53]; updated based on personal discussion with the author in 2014).

\begin{tabular}{lc}
\hline Production Process & Energy/Mass Unit \\
\hline Production of synthetic rubber (SBR) & $43.4 \mathrm{kWh} / \mathrm{kg}$ \\
Calorific value of scrap tires & $9.0 \mathrm{kWh} / \mathrm{kg}$ \\
Needed energy for the pre-crushing of whole scrap tires into coarse chips (average size $50 \mathrm{~mm})$ & $0.1 \mathrm{kWh} / \mathrm{kg}$ \\
Needed energy for the crushing of whole scrap tires into small particles (average size 0.5-1.5 mm) & $1.2 \mathrm{kWh} / \mathrm{kg}$ \\
Needed energy for the crushing of whole scrap tires into fine particles (average size smaller than $0.4 \mathrm{~mm})$ & $2.5 \mathrm{kWh} / \mathrm{kg}$ \\
\hline
\end{tabular}

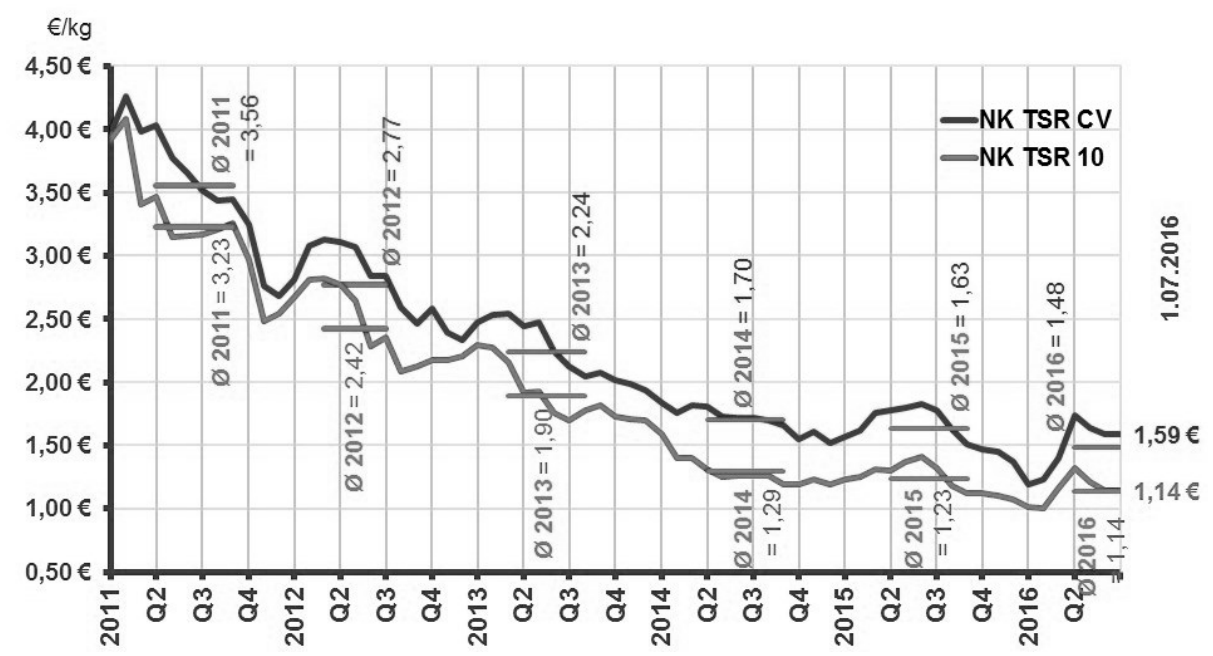

Figure 7. Natural rubber price quotations at MRE *, monthly average (* Malaysian Rubber Exchange, fob-price, July-value = moving four-week-average; graphs represent different rubber qualities used in tires; TSR: technically specified rubber) [54].

According to the energy demand and the prices for material and energy, a recycler may decide which recycling processing method to prioritize, e.g., tire retreading, energy recovery (tire in a whole or shredded) in industrial kilns, or landfilling. As seen in Figure 7, the volatility of the price for natural rubber may change the favored recycling process. For example, when the price for natural rubber is low, rubber products manufacturers may prefer to buy virgin material instead of material reuse or retreading. Similarly, when fuel prices are low, cement kilns may prefer other energy sources than used 
tires. Nevertheless, cascading material is seldom based on economical savings only. Indeed, it is a balance between environmental and economic drivers and cannot be assessed without each other. More economic profit may lead to more environmental damage and vice versa. The idea is to find a balance that does not neglect any of the two sides. This balance is, however, quite subjective and often political constraints are involved. In the case of scrap tires, most countries have banned landfilling. Therefore, other options must be considered, which in turn influence the cascading at the EOL. This case is representative for many other waste flows, where the open-loop recycling flows may change rapidly depending on the volatile market demand. Hence a dynamic system of supply chains is required to address this.

\subsection{Case Study: Suspension Control Arms}

The second case study addresses Suspension Control Arms (SCA), an automotive component that is not yet remanufactured at industry level; hence the knowledgebase is less developed than in the tire case. Nevertheless, the case of SCA remanufacturing provides the rare opportunity to observe whether and how a new automotive component gets remanufactured and may become a future standard remanufactured spare part. The primary data for this case was collected by one of the authors through a face-to-face interview in 2015 and extensive e-mail exchange in 2016 with the patent holder for the SCA remanufacturing process referenced in the following. The primary data is augmented with additional information to critically evaluate the validity of the collected data (e.g., $\mathrm{CO}_{2}$ emission reduction by SCA remanufacturing). The case shows how different stakeholders of the automotive EOL supply chain can contribute to extended lifecycles and the circularity of material flows. Admitting third parties to access EOL supply chains allows for better cascading and improved PLCs in terms of both value and resource conservation.

SCAs are an integral part of independent suspensions in modern vehicles. SCAs are made of steel or aluminum casts [55]. Although aluminum has a higher material value than steel, the relative low (material) value of SCAs stems from the value of other car components, especially regularly reused and remanufactured parts, which are more complex in their material composition and their functions (e.g., starters, alternators, injection valves, or car electronics). Considering the production of aluminum from bauxite in the following, this is energy intensive and results in hazardous by-products such as red mud [56]. In the cascade perspective (see Figure 8), aluminum SCAs leave the product, in this case a car, directly towards the recycling level of the cascade (3). At the recycling level, the SCA will ideally be recycled with other aluminum scrap, leading to a relatively pure secondary material. Although, lower qualities may result from this recycling stream as well.

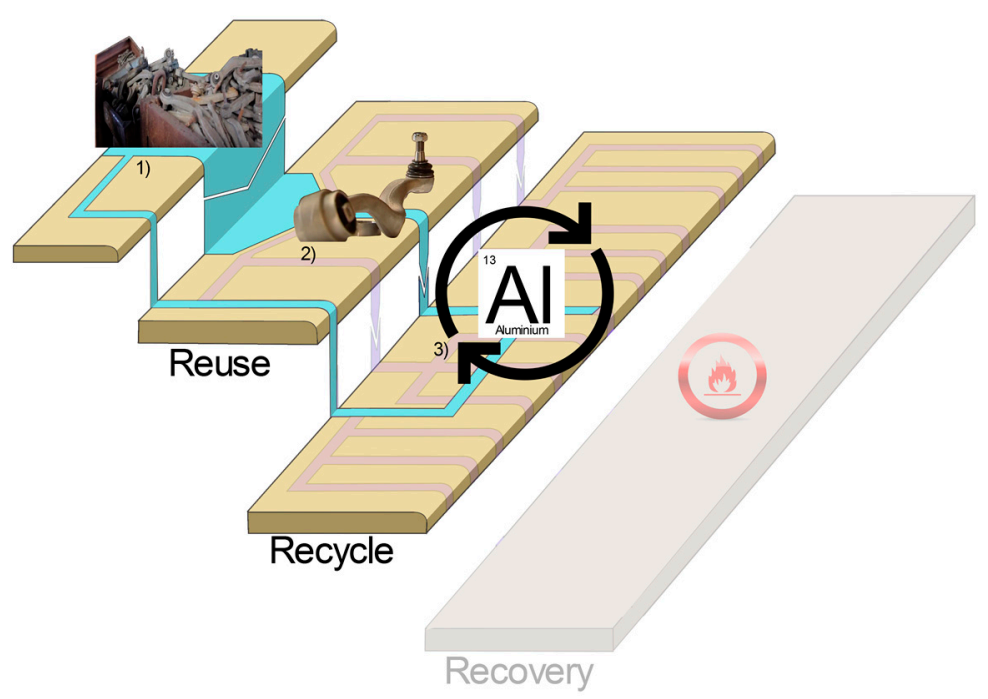

Figure 8. Suspension Control Arms Cascade Use. 
SCAs are a new product for remanufacturing. Therefore, two main aspects require closer attention: (a) the (technical) remanufacturing process, and (b) the acquisition of used parts. Without an economically feasible process, remanufacturing cannot compete with new spare parts. Therefore, besides delivering identical quality to new parts, remanufacturing processes have to ensure lower costs than new spare part production and coincide with the right market conditions of growth rate and demand [57].

Despite the circumstances of lower material value, the Belarus Vitaly Katok invented and patented a process and tool for the remanufacturing of SCAs [58-60]; Figure 9 shows a SCA remanufactured by this process. Since 2015, Katok is present at the U.S. market where they aim to establish a remanufacturing business for aluminum SCAs. This product can substitute new spare parts and lower related environmental impacts. The company estimates the number of yearly worn out aluminum control arms in the USA and the EU at 200 million [61]. If one control arm weighs approx. $2 \mathrm{~kg}$ (difficult to estimate due to great variety of control arm designs), 200 million control arms aggregate to ca. 400,000 tons. Considering further that this weight equals the aluminum content, the primary production would have caused 6.12 million tons of $\mathrm{CO}_{2}$ emissions. Recycling 200 million control arms would cause an additional 280,000 tons of $\mathrm{CO}_{2}$ which are $95.4 \%$ less than primary production (numbers from [62]). Although recycling already reduces the $\mathrm{CO}_{2}$ for aluminum production to approx. $5 \%$ of primary production, reuse can reduce this amount even further. Assuming a reuse rate of $20 \%$, control arms remanufacturing can save another 56,160 tons of $\mathrm{CO}_{2}$ emissions per year. Assuming $90 \%$ reusability, the saving potential would increase to 252,720 tons of $\mathrm{CO}_{2}$ per year.

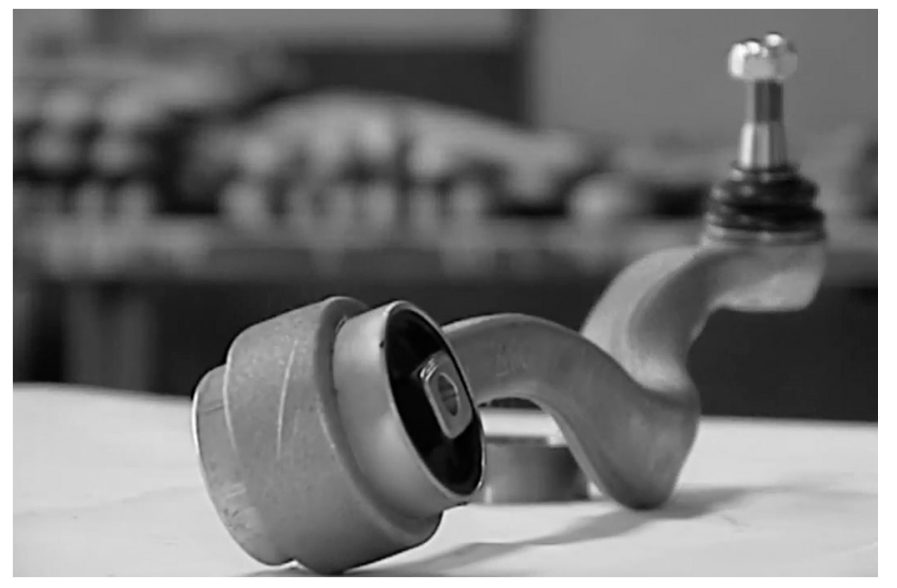

Figure 9. Suspension Control Arm remanufactured with Katok's patented process @ Katok.

The second aspect is the acquisition of used parts (so called cores) for remanufacturing. Generally, the acquisition of cores is a challenge for the remanufacturing industry. Eventually, the industry agrees with the mantra 'who owns the core, owns the business'. For this reason, remanufacturers try to establish reverse logistics and CLSCs in order to improve core supply for production. However, CLSCs for SCAs do not exist yet. For this reason, Katok needs to convince dismantlers to remove SCAs from ELVs and convince repair shops to separate SCAs from general metal waste; finally, they must ensure that the dismantlers sell these SCAs to them instead of material recyclers. Likewise, core brokers who deal with used parts need to identify a benefit in dealing with SCA cores in order to increase return rates. So far, the supply with cores does not seem to be an issue [63]. However, in case the remanufacturing of SCAs increases, other stakeholders could be attracted to this market and the competitive landscape could change. Such growing interest may increase the amount of remanufactured parts but would further increase the relevance of procurement strategies in order to maintain sensible economies of scale. 
On the one hand, there is the innovation potential of independent remanufacturers (IRs). They innovate and invest in new processes to remanufacture products, not remanufactured before. On the other hand, there are challenges such as product availability and the overall economics of remanufacturing. Despite necessary investments and challenges, independent EOL stakeholders lead the way towards the remanufacturing of new parts. By postponing material recycling, independent remanufacturers contribute to resource conservation. Therefore, the independent remanufacturers are already an integral part of more comprehensive PLCs. When OEMs manage their PLCs, they consider independent remanufacturers solely when they form part of the hierarchy organization, such as in contractual relationships (see, for example, [64]).

\section{Discussion: Implications of Cascading Use for the EOL-Management}

The case studies demonstrate the complexity of decisions associated with different End-Of-Life scenarios; they further explain how the cascade use methodology can improve the understanding and therefore the management of PLCs (Research Question 1). In the following, the second guiding research question, 'How can a cascade use methodology contribute to a more sustainable management of product and material lifecycles?' is discussed.

The presented cases illustrate factors that influence decisions about EOL options, i.e., cascading opportunities. Manufacturers can design their products for circular PLCs (e.g., design for reuse/recycling) and implement Closed-Loop Supply Chains (CLSC) in order to benefit from additional added values, for example due to reuse via remanufacturing. Accordingly, the mass flows through a cascading use may change towards the manufacturer's CLSC. In addition, new technologies or changing market demands may influence the mass flows within one cascade. Thus, other PLCs and Supply Chains may gain more of the mass flows; for example, in the Suspension Control Arms case, as closed-loop case study, mass flows may shift towards reuse instead of recycling. Similarly, in the tire case, representing the open-loop case, the demand from cement kilns for tires as refuse derived fuel may vary due to changing energy prices or due to policy intervention, and this is not a favored solution for cascading since energy recovery always remains the last cascade by definition. Although, policy often pursues sustainability rather than economic objectives, the effects on mass flows are similar. The emergence of the circular economy debate in Europe and regulations such as the Dodd-Frank Act in the US influence the decisions of how to cascade products and materials. All identified influences, such as market actor's actions (e.g., closed-loop vs. forward SCs), changing market demand or policy interventions, may cause mass flows to shift between cascading use options.

Nevertheless, the cases showed that there is added value at various levels of a cascade in both open-loop and closed-loop lifecycle, besides environmental benefits due to resource and energy savings. The emergence of independent remanufacturers at the EOL shows that there exists untapped added value at the reuse level of the cascade. At both the reuse and recycling level, markets may involve in the management of EOL products or materials. OEMs entering remanufacturing markets to benefit from additional PLCs support the underlying added value proposition. Usually, once resources reach the recycling level, third-party organizations take over the material streams. Consequently, the closed-loop perspective in terms of products and in terms of supply chains is more dominant at the reuse level, while open-loop views (materials and supply chains) dominate at the recovery level. Nevertheless, important exceptions exist and show promising opportunities for sustainability improvements. However, in cases where sustainability objectives dominate, the example case of cascading use of tires showed that policy intervention might be relevant given that resource and energy price volatility may eliminate profits.

The outlined cascade use methodology implies that additional stakeholders manage those new emerging lifecycles too. Due to the complexity at the EOL, it is hardly possible that one OEM or the SC owner manages all available EOL options. Although particular SC actors may be motivated to discourage EOL alternatives that are not provided by their own SC [65]. The cases demonstrate that different stakeholders provide different EOL options. Of course, CLSCs offer the opportunity 
to control product and material flows to some extent. Although, this control does not necessarily ensure a cascading use in the sense of a more sustainable resource management. CLSCs might both enable and hinder more sustainable EOL options. The issue of the CLSC as a potentially inconsistent solution for more sustainable EOL options is similar to the wicked character [66] identified for sustainable SC management; wickedness is understood as diverging problem definitions and accordingly diverging solution approaches. Similarly, many different stakeholders with diverging interests intervene in a highly complex EOL that has no clear indicator for the most sustainable and overall beneficial solution. Because the former SC owner not necessarily provides such solution, a more comprehensive management of EOL options would require SC owners to reconsider their role at the EOL. Figure 10 summarizes the findings and highlights implications for an improved management of PLCs as discussed in the following.

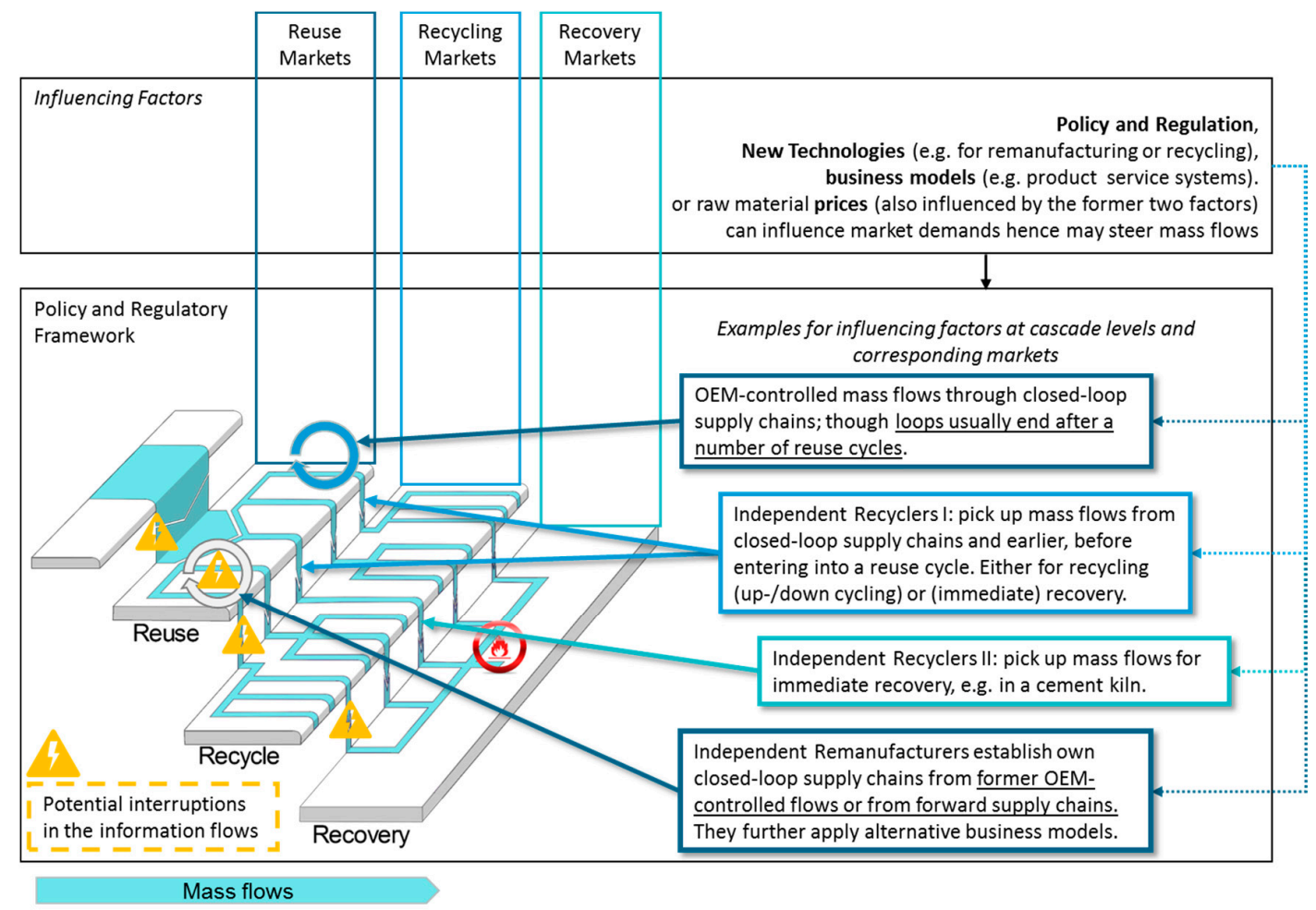

Figure 10. Examples for different influencing factors affecting cascade use mass flows (own figure).

A cascading utilization of materials and products connects different SCs that emerge from the EOL of a product. Those SCs could either be CLSC usually designed by OEMs together with the product at its Begin-Of-Life (OEM-controlled flows in Figure 10), or SCs with a starting point at a particular product, component or material EOL. The latter SCs are usually established by third-parties. In the case of remanufacturing, such SCs may become CLSC while they remain at the reuse level of the cascade (independent remanufacturer in Figure 10). This illustrates the emergence of a complex system rather than a clear, single SC process; the cascade use methodology considers a complex system with various external influences that connects various SCs at certain stages and in certain points of the PLC. These selective connections throughout the cascade may stem from 'leakages' of one CLSC that take a different route than the CLSC through the cascades; or the connections consist of SCs deriving from a forward oriented SC. The integrated management of both CLSCs and forward SCs may end at a higher level of the cascade. At this stage, a third-party usually takes over and manages the reuse or recycling SC further (recyclers I and II, and remanufacturers in Figure 10). An increasingly dynamic system emerges that is influenced by external factors and that challenges linear PLC processes. In such dynamic systems, original and new EOL stakeholders, may create an 'assortment of EOL solutions'. 
The example of independent remanufacturing showed how independent remanufacturers ensure a greater assortment of remanufactured spare parts. Additional EOL options may lead to longer product life and less environmental damage. In a PLC following the cascade use methodology, the former SC owner might not have the strongest position in consecutive PLC SCs. Nevertheless, the former SC owner still plays an important role for cascading use. This important role derives from its position in the supply chain and its product knowledge and information regarding technologies, materials and whereabouts at different times. The information chain is usually interrupted at a particular EOL. One key challenge at this stage is to identify how SC owners can benefit from such complex systems emerging from a cascading use perspective, for example, to motivate them to share information. Without a clearly identified benefit, the narrower perspective on separate CLSC may dominate. CLSCs for particular PLCs ensure resource control first, whether they provide for greater assortments and more sustainable solutions is not that clear.

We expect that managerial decisions that imply less control over EOL options would not become easy for OEMs, especially if closed-loops are already implemented. Acknowledging the reality of product and material cascades and implementing the cascade use methodology enables OEMs to identify different EOL options, which may provide opportunities beyond existing CLSCs.

If the PLC management would consider the broad variety of EOL options in addition to the originally designed lifecycles, it may also contribute to environmental and economic benefits that go beyond the originally designed lifecycles. Especially in case of durable products such as cars, not all potential EOL options may be known at the BOL stage. Therefore, the management of PLCs needs to adjust to new circumstances, for example to new technologies or changing market demand. It is essential to identify and recognize additional means to facilitate new lifecycles. This includes the provision of spare parts and specifications for remanufacturing; one approach could be licensing for third markets where OEM provide knowledge and technologies beyond their original SC and outside their brand's markets. Many used products are traded globally, such as used cars and refurbished mobile handsets. Hence, products appear on markets where OEMs are not immediately present or where customers cannot afford original spare parts and high-end services. By facilitating local or regional reuse and recycling through third parties, manufacturers can contribute to sustainability objectives without compromising their brands and sales in focal markets. However, OEMs may not be able, willing or motivated to identify benefits in such new and/or unusual markets. Furthermore, OEMs most likely provide the data necessary for an improved PLC management only along those parts of the PLC and SC that they control. Therefore, information flows are interrupted and third parties must identify alternative ways to acquire and manage the information necessary for an effective management of extended PLCs. In areas such as automotive remanufacturing, independent remanufacturers may have their own information systems in place to manage their SCs. Furthermore, the PLM domain already provides solution approaches to address some of these issues. Nevertheless, these solution approaches may not withstand the confrontation with the complex reality as depicted in the previously discussed case studies. The research on PLM should therefore extend to the investigation of how third party SCs of potentially many different actors manage the challenge of missing OEM product data, how they overcome related obstacles and how to support such SCs. The questions of support for such SCs may well be motivated, from a managerial as well as from a governmental perspective.

The cascading use methodology broadens the perspective on the EOL, addressing both closedand open-loop cycles. Due to the complexity at the EOL, OEMs may solely manage distinct cascades of the PLC and are rather closed-loop orientated. Examples are the remanufacturing and recycling activities of vehicle manufacturers and their suppliers, who remanufacture those components that they manufactured in-house and recycle the remaining parts of the car for reintegration into a (new) car. However, significant quantities of the initial mass flow never return to the OEM and some products are not (yet) or not anymore of interest to the OEM. Therefore, understanding the complexity at the EOL, especially at the blurry transition interface between MOL and EOL, is an opportunity for extended product and material lifecycles. While OEMs do not necessarily have to manage these additional 
lifecycles themselves, they play a crucial role whether additional lifecycles emerge, especially at higher levels of cascading use such as remanufacturing. The translation of such perspective into business strategies and the management of lifecycles would benefit the environment as well as the economy. It is essential to think beyond particular product EOLs, originally designed PLCs and CLSC, and to incorporate new solutions and third markets into a solution system (Research Question 2).

Nevertheless, additional case studies are required to (a) evaluate the implications of the cascade use methodology for organizations and stakeholders at reuse and recycling levels, and (b) to identify improved managerial and business strategies for the consideration of cascade utilization in PLCs. Managerial strategies are of special importance in order to demonstrate how to benefit from emerging PLCs that are outside the former PLC manager's control. Therefore, PLC research should also consider the different stakeholders at the EOL of components and products in more detail. This is especially important, because market organizations, in contrast to the integrated organization of a CLSC, provide for alternative EOL options. Independent market actors indicate economic benefits in the EOL. These benefits are incentives for all market actors to extend PLC perspectives hence to adopt their business strategy towards more sustainable SCs.

\section{Conclusions and Research Outlook}

This paper discussed the variety of product lifecycles and End-Of-Life perspectives from a marketing and a technical perspective addressing closed-and open-loop lifecycles. It further explained how the cascade use methodology can extend the EOL perspective in PLCs and illustrated the cascading use with two automotive case studies, one exemplary representing an open-loop as scrap tire case, the other one representing the closed-loop case. Thereby, this paper contributes to the discussions on how to achieve a circular economy and the cascade use methodology aims at advanced PLC approaches. The cascade use methodology applied to the new industrial case studies verifies how different and essential EOL stakeholders' extended lifecycles are for a truly circular economy. These stakeholders not only include classical waste management organization such as recyclers, but also independent remanufacturers, on primary as well as on secondary markets. Original Equipment Manufacturers and Closed-Loop Supply Chains are important to close PLCs, though mass flows diverge from Supply Chains, whether open- or closed-loop systems. Therefore, a circular economy requires SC owners to identify their product's mass flows and EOLs in order to facilitate EOL solutions beyond CLSCs. Despite their importance for improved resource utilization, OEM- or CLSC-centric approaches neglect the complexity and diversity at the EOL; utilizing this EOL complexity is imperative in order to build a truly circular economy. Accordingly, policy approaches should also encourage different EOL stakeholders and advocate a healthy competition for EOL solutions.

The cascading use methodology provides a promising approach to extend the EOL perspective in a structured form of PLCs (Research Question 1) and to identify additional or new EOL solutions for products and materials. Stakeholders at the product or material EOL, whether OEMs or third parties, have to identify an economic benefit in order to process mass flows in a circular economy manner. The existence of third parties at the EOL is a strong indicator for economic benefits, for the same reason OEMs involve in remanufacturing. However, the cascade use methodology does not focus on single SCs or OEM-related PLCs but rather identifies stakeholders at merging and diverging SCs at product and material EOLs. Identifying EOL stakeholders highlights additional EOL options, not yet considered in the original PLC, and therefore the cascade use methodology provides a more comprehensive perspective on the business opportunities emerging at the EOL in the form of iterative, cascading PLCs (Research Question 2).

Future research in the context of cascading utilization needs to look at implications of the cascade use methodology not only on the Begin-Of-Life but on Mid-Of-Life phases. This may include the way in which SCs in the biomass domain are managed in a sustainable way or how stakeholders in the domain adopt to changes in resource availability and changing EOL mass flows. In addition, the implications of the cascading use methodology for the management of PLCs require more research. For example, 
the implications of cascade utilization require research to reconsider the system boundaries of lifecycle information management systems. Additional case studies as well as research in operations and on forward and closed-loop SCs are promising focal areas of these future research activities. Such research is necessary in order to evaluate business strategies that can present in detail the sustainability benefits, stemming from the cascade use methodology in the domain of (durable) products and materials. It has to be mentioned that a comprehensive discussion in all three sustainability dimensions is necessary in the future, not only environmental and economic as presented in this study, but also social which requires similar attention.

Acknowledgments: The authors from the University of Oldenburg were financially supported by the German Federal Ministry of Education and Research (BMBF) in the Globaler Wandel research scheme (Grant No. 01LN1310A). The authors are grateful for the feedback Stefan Wellsandt from BIBA-Bremer Institut für Produktion und Logistik GmbH provided on earlier versions of this article. Further, the authors especially thank Vitaly Katok for his confidence and for sharing details on his remanufacturing business case.

Author Contributions: Matthias Kalverkamp developed the cascade use methodology based on preliminary work from Alexandra Pehlken regarding cascade use; Thorsten Wuest assisted the methodology development regarding PLM; Alexandra Pehlken conceived the tire case, Matthias Kalverkamp conducted the suspension control arms case; Matthias Kalverkamp analyzed the case studies assisted by Thorsten Wuest; Matthias Kalverkamp wrote the paper.

Conflicts of Interest: The authors declare no conflict of interest. The founding sponsors had no role in the design of the study; in the collection, analyses, or interpretation of data; in the writing of the manuscript, and in the decision to publish the results.

\section{References and Notes}

1. Ruggieri, A.; Braccini, A.; Poponi, S.; Mosconi, E. A Meta-Model of Inter-Organisational Cooperation for the Transition to a Circular Economy. Sustainability 2016, 8, 1153. [CrossRef]

2. Subramoniam, R.; Huisingh, D.; Chinnam, R.B. Remanufacturing for the automotive aftermarket-strategic factors: Literature review and future research needs. J. Clean. Prod. 2009, 17, 1163-1174. [CrossRef]

3. UNEP. Metal Recycling: Opportunities, Limits, Infrastructure: A Report of the Working Group on the Global Metal Flows to the International Resource Panel; UNEP: Nairobi, Kenya, 2013.

4. Agrawal, A. Turn Your Reverse Supply Chain into a Profit Center. 2012. Available online: http://www. supplychainquarterly.com/topics/Strategy /201201reverse/ (accessed on 23 July 2014).

5. Dodd-Frank Wall Street Reform and Consumer Protection Act: Dodd-Frank Act. Pub. L. 111-203, USA, 2010.

6. European Union. Being Wise with Waste: The EU's Approach to Waste Management; Publications Office of the European Union: Luxemburg, 2010.

7. Östlin, J.; Sundin, E.; Björkman, M. Product life-cycle implications for remanufacturing strategies. J. Clean. Prod. 2009, 17, 999-1009. [CrossRef]

8. Cooper, D.R.; Gutowski, T.G. The Environmental Impacts of Reuse: A Review. J. Ind. Ecol. 2017, 21, 38-56. [CrossRef]

9. European Commission. Closing the Loop-An EU Action Plan for the Circular Economy. COM (2015) 614 Final. 2015. Available online: http:/ / eur-lex.europa.eu/legal-content/EN/TXT/?uri=CELEX:52015DC0614 (accessed on 5 July 2016).

10. Patala, S.; Hämäläinen, S.; Jalkala, A.; Pesonen, H.-L. Towards a broader perspective on the forms of eco-industrial networks. J. Clean. Prod. 2014, 82, 166-178. [CrossRef]

11. Moreno, M.; de los Rios, C.; Rowe, Z.; Charnley, F. A Conceptual Framework for Circular Design. Sustainability 2016, 8, 937. [CrossRef]

12. Guide, V.D.R.; van Wassenhove, L.N. The Evolution of Closed-Loop Supply Chain Research. OR FORUM. Oper. Res. 2009, 57, 10-18. [CrossRef]

13. Linder, M.; Williander, M. Circular Business Model Innovation: Inherent Uncertainties. Bus. Strateg. Environ. 2015. [CrossRef]

14. Tukker, A. Product services for a resource-efficient and circular economy-A review. J. Clean. Prod. 2015, 97, 76-91. [CrossRef]

15. Barkmeyer, M.; Kaluza, A.; Pastewski, N.; Thiede, S.; Herrmann, C. Assessment of End-Of-Life Strategies for Automation Technology Components. Procedia CIRP 2017, 61, 34-39. [CrossRef] 
16. Borsato, M. Bridging the gap between product lifecycle management and sustainability in manufacturing through ontology building. Comput. Ind. 2014, 65, 258-269. [CrossRef]

17. Tibben-Lembke, R.S. Life after death: Reverse logistics and the product life cycle. Int. J. Phys. Distrib. Logist. Manag. 2002, 32, 223-244. [CrossRef]

18. Kotler, P.; Keller, K.L. Marketing Management, 13th ed.; Pearson Prentice Hall: Upper Saddle River, NJ, USA, 2009.

19. Meffert, H.; Burmann, C.; Kirchgeorg, M. Marketing: Grundlagen Marktorientierter Unternehmensführung; Springer: Wiesbaden, Germany, 2015.

20. Levitt, T. Exploit the Product Lifecycle. Harv. Bus. Rev. 1965, 43, 81-94.

21. Jun, H.-B.; Kiritsis, D.; Xirouchakis, P. Research issues on closed-loop PLM. Comput. Ind. 2007, 58, 855-868. [CrossRef]

22. Duda, M.; Shaw, J.S. Life cycle assessment (product life cycle). Society 1997, 35, 38. [CrossRef]

23. International Organization for Standardization (ISO). Environmental Management_Life Cycle AssessmentPrinciples and Framework; International Organization for Standardization: Geneva, Switzerland, 2006.

24. Schuh, G.; Rozenfeld, H.; Assmus, D.; Zancul, E. Pro cess oriented framework to support PLM implementation. Comput. Ind. 2008, 59, 210-218. [CrossRef]

25. Terzi, S.; Bouras, A.; Dutta, D.; Garetti, M.; Kiritsis, D. Product lifecycle management—From its history to its new role. IJPLM 2010, 4, 360. [CrossRef]

26. Alderson, W.; Martin, M.W. Toward a formal theory of transactions and transvections. J. Mark. Res. 1965, 2, 117-127. [CrossRef]

27. Stark, J. Product Lifecycle Management: 21st Century Paradigm for Product Realisation; Springer: London, UK, 2011.

28. Svensson, G. The theoretical foundation of supply chain management. Int. J. Phys. Distrib. Logist. Manag. 2002, 32, 734-754. [CrossRef]

29. Directive 2000/53/EC of the European Parliament and of the Council of 18 September 2000 on End-Of Life Vehicles. Directive 2000/53/EC, 2000, pp. 3-30.

30. 2008/98/EC of the European Parliament and of the Council of 19 November 2008 on Waste and Repealing Certain Directives. Directive 2008/98/EC, 2008, pp. 34-42.

31. Wellsandt, S.; Nabati, E.; Wuest, T.; Hribernik, H.; Thoben, K.-D. Product Lifecycle Models: A survey. Int. J. Prod. Lifecycle Manag. 2017, under review.

32. Hu, G.; Bidanda, B. Modeling sustainable product lifecycle decision support systems. Int. J. Prod. Econ. 2009, 122, 366-375. [CrossRef]

33. Gehin, A.; Zwolinski, P.; Brissaud, D. A tool to implement sustainable End-Of-Life strategies in the product development phase. J. Clean. Prod. 2008, 16, 566-576. [CrossRef]

34. Ziout, A.; Azab, A.; Atwan, M. A holistic approach for decision on selection of End-Of-Life products recovery options. J. Clean. Prod. 2014, 65, 497-516. [CrossRef]

35. Weiland, F.J. European automotive remanufacturing: Where is it heading? In European Automotive Remanufacturing: Technical Trends \& Market Development; Weiland, F.J., Ed.; FJW Consulting: Cologne, Germany, 2012; pp. 129-164.

36. EC JRC Institute for Environment and Sustainability. International Reference Life Cycle Data System (ILCD) Handbook-General Guide for Life Cycle Assessment_Detailed Guidance; European Commission_Joint Research Centre-Institute for Environment and Sustainability: Luxembourg, 2010.

37. Haberl, H.; Geissler, S. Cascade utilization of biomass: Strategies for a more efficient use of a scarce resource. Ecol. Eng. 2000, 16, 111-121. [CrossRef]

38. Geldermann, J.; Kolbe, L.M.; Krause, A.; Mai, C.; Militz, H.; Osburg, V.-S.; Schöbel, A.; Schumann, M.; Toporowski, W.; Westphal, S. Improved resource efficiency and cascading utilisation of renewable materials. J. Clean. Prod. 2016, 110, 1-8. [CrossRef]

39. Ahmadi, L.; Young, S.B.; Fowler, M.; Fraser, R.A.; Achachlouei, M.A. A cascaded life cycle: Reuse of electric vehicle lithium-ion battery packs in energy storage systems. Int. J. Life Cycle Assess. 2015. [CrossRef]

40. Guide, V.D.R.; Wassenhove, L.N. Closed-Loop Supply Chains: An Introduction to the Feature Issue (Part 1). Prod. Oper. Manag. 2006, 15, 345-350. [CrossRef]

41. Aydin, R.; Kwong, C.K.; Ji, P. A novel methodology for simultaneous consideration of remanufactured and new products in product line design. Int. J. Prod. Econ. 2015, 169, 127-140. [CrossRef] 
42. Martínez-Olvera, C. Methodology for realignment of supply-chain structural elements. Int. J. Prod. Econ. 2008, 114, 714-722. [CrossRef]

43. Daniel, V.; Guide, R.; Jayaraman, V. Product acquisition management: Current industry practice and a proposed framework. Int. J. Prod. Res. 2000, 38, 3779-3800. [CrossRef]

44. Ellen MacArthur Foundation. Towards the Circular Economy: An Economic and Business Rationale for an Accelerated Transition. 2013, Volume 1. Available online: https://www.ellenmacarthurfoundation. org/publications / towards-the-circular-economy-vol-1-an-economic-and-business-rationale-for-anaccelerated-transition (accessed on 13 July 2013).

45. Lebreton, B. Strategic Closed-Loop Supply Chain Management; Springer: Berlin/Heidelberg, Germany, 2007.

46. Thierry, M.; Salomon, M.; van Nunen, J.; van Wassenhove, L. Strategic Issues in Product Recovery Management. Calif. Manag. Rev. 1995, 37, 114-135. [CrossRef]

47. Ellen MacArthur Foundation. Towards the Circular Economy: Accelerating the Scale-Up across Global Supply Chains. 2014, Volume 3. Available online: https://www.ellenmacarthurfoundation.org/assets / downloads/publications/Towards-the-circular-economy-volume-3.pdf (accessed on 14 July 2016).

48. Ferguson, M.E.; Toktay, L.B. The Effect of Competition on Recovery Strategies. Prod. Oper. Manag. 2006, 15, 351-368. [CrossRef]

49. ACtronics. Volvo-Magneti Marelli Gasklephuis. 2016. Available online: http://www.actronics.eu/shop/ product/volvo-magneti-marelli (accessed on 28 July 2016).

50. Pehlken, A.; Essadiqi, E. Scrap Tire Recycling in Canada; MTL (CF): Ottawa, ON, Canada, 2005.

51. Dunn, J.R.; Jones, R.H. Automobile and truck tires adapt to increasingly stringent requirements. Elastomerics 1991, 137, 11-18.

52. Asplund, J. Scrap Rubber: An Unpredictable Waste or a Useful Raw Material. In Proceedings of the Rubber in the Environmental Age-Progress in Recycling, Shawbury, UK, 18 November 1996; Rapra Technology Ltd.: Shawbury, UK, 1996.

53. Reschner, K. Altreifen-Recycling. Unpublished work, 2002.

54. Wirtschaftsverband der Deutschen Kautschukindustrie e.V. Naturkautschuk-Notierungen Täglich: MRE Monatsdurchschnitte. Adapted from Malaysian Rubber Stock Exchange (2011-2016): Frankfurt, Germany, 2016. Available online: http:/ / www.wdk.de/de/index.html (accessed on 1 July 2016).

55. Adamcyk, D.; Fischer, M.; Schüller, K. Suspension Arms, Steel versus Aluminium, Where are the Benefits? Encycl. Autom. Eng. 2004. [CrossRef]

56. Ayres, R.U.; Holmberg, J.; Andersson, B. Materials and the Global Environment: Waste Mining in the 21st Century. MRS Bull. 2001, 26, 477-480. [CrossRef]

57. Atasu, A.; Sarvary, M.; van Wassenhove, L.N. Remanufacturing as a Marketing Strategy. Manag. Sci. 2008, 54, 1731-1746. [CrossRef]

58. Katok, V.V. Apparatus for Repairing Control Arms of Automotive Suspension. U.S. Patent 8,950,234 B2, 10 February 2015.

59. Katok, V.V. Apparatus and Methods for Repairing Control Arms of Automotive Suspension. U.S. Patent 8,516,673 B1, 27 August 2013.

60. Katok, V.V. Apparatus and Method for Repairing Control Arms of Automotive Suspension. EP 2,695,754 B1, 27 April 2016.

61. Katok, V.V. Presentation for Potential Business Partner: Alyukat.by-Ecologically Clean Product. Unpublished work, 2015.

62. Schlesinger, M.E. Aluminum Recycling, 2nd ed.; Taylor and Francis: Hoboken, NJ, USA, 2013.

63. Katok, V.V. Katok's Remanufacturing Activities in the US Regarding Suspension Control Arms. Unpublished work, 2016.

64. Lind, S.; Olsson, D.; Sundin, E. Exploring inter-organizational relationships in automotive component remanufacturing. J. Remanuf. 2014, 4, 5. [CrossRef] 
65. Rizzi, F.; Bartolozzi, I.; Borghini, A.; Frey, M. Environmental Management of End-Of-Life Products: Nine Factors of Sustainability in Collaborative Networks. Bus. Strateg. Environ. 2013, 22, 561-572. [CrossRef]

66. Meckenstock, J.; Barbosa-Póvoa, A.P.; Carvalho, A. The Wicked Character of Sustainable Supply Chain Management: Evidence from Sustainability Reports. Bus. Strateg. Environ. 2016, 25, 449-477. [CrossRef] 